congested. The kidneys weighed $8 \mathrm{oz}$. each, and were unusually bulky; their capsules were free and their cortical substance was pale, but their pyramids were congested and almost of a black colour. The stomach contained half a pint of dark fluid and some portions of partially digested food; its mucous lining was intensely congested. The skull was thickened in front, and adherent to the dura mater. The sinuses were empty, and the arachnoid was thickened and of a milky appearance. The whole brain weighed $60 \mathrm{oz}$., and was generally anæmic. The ventricles were fully occupied by clear fluid.

In the case of B. B-, it seems tolerably evident that death was to be ascribed to paralysis of the heart, which was in turn to be ascribed to the inhibitory influence of chloral. Like chloroform, chloral appears to have the power of reducing the natural force of action of the heart, and sometimes of stopping the play of the organ. Facts are not wanting to indicate that it exerts this power through the sympathetic system, and, indeed, that the inferior cervical ganglion is the chief centre through which it operates. Du Bois Reymond showed that applications to this ganglion could be made to accelerate or impede cardiac contractions, and that it was in intimate relation with the pneumogastric nerves ("Comptes Rendus," March 25th, 1867) and with the spinal cord. It is interesting to note how identical the post-mortem appearances noted in the case of $B$. B- are with those which have been found in many cases of death after chloroform.

I have felt obliged in this paper to compress, as much as might be, my observations on the inconveniences and dangers of chloral, and to omit many curious and instructive details. I have perhaps said enough, however, to vindicate the thesis-that serious hazards attend its employment, and that it ought only to be resorted to with medical advice.

March ind, 1871.

\section{TWO CASES OF OVARIOTOMY.}

\section{By A. C. C. D E R E N Y,

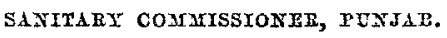

Kurmoo, aged thirty, was admitted into the Multan Dispensary on the 1st May, 1866, in a very anæmic state. She had suffered from an ovarian tumour of great size for some years. She had been tapped six times, the last time on the 16th March, when, it is said, three gallons of "coffeegrounds" fluid was removed. The operation was followed by great prostration. The sac refilled rapidly; and after a fortnight or so it had nearly attained its original size. As her life had now become a burden to her, $\mathrm{I}$ consented to her earnest entreaty to be relieved of the tumour at any risk.

I operated on the 20th May, assisted by Drs. Greenhow, Wood, and Alcock. The tumour was found firmly attached all over its anterior surface by very strong leathery adhesions, which required considerable force to break up. The right half of the omentum presented a blackish diseased appearance, the contained glands being soft, black, and pultaceous. The pedicle was about three inches long. It was tied in two paxiels with a silk ligature, and its extremity was brouglit out and fixed in the external wound with a needle in the ordinary way. The diseased portion of the omentum was partially removed, the proximity of the colon having deterred me from a more complete removal of it. The patient bore the operation very well, and appeared to be going on very well for nine hours afterwards. She had a quiet sleep for some hours. Towards evening, however, symptoms of peritonitis supervened; and she died the following morning at three o'clock.

A post-mortem examination revealed a very circumscribed peritonitis, confined entirely to the right side of the abdomen and encircling the diseased part of the omentum. The peritoneum external to the diseased circle was paler than usual. If the patient had lived longer, the whole of the peritoneum would probably have become involved in the inflammation; but the fact that in the first instance the inflammation was so strictly limited to the parts adjacent to the diseased omentum suggests that a blood-poison, derived probably from the softened mesenteric glands, was the immediate cause of the fatal result in this case. Later experience has convinced me that the diseased structures might have been removed with comparative safety. The tumour was multilocular; the solid portion weighed $29 \mathrm{lb}$.

Miriam, aged thirty-three, a Mussulmani woman, was admitted into the Multan Dispensary on the 4th of May, 1867. She had suffered from an ovarian tumour for six years. She was tapped in the dispensary on the 10th of December, 1866. The tumour refilled very rapidly. On admission she was in a very low state, being greatly emaciated and anæmic; ankles œdematous; pulse small and thready-120 to 140; great dyspncea, caused by the pressure of the tumour on the diaphragm and the displacement of the heart upwards. Her girth, measured round the umbilicus, was fifty-one inches; from the ensiform cartilage to pubes, thirty-two inches. She complained of distressing thirst; her tongue was red, and presented numerous deep, sharp-edged fissures, as if cut with a knife; her urine was free from albumen. She was in so low a state that I shrank from an operation having for its object the removal of the tumour, and I contented myself with tapping. On the 10th of May I drew off twenty-eight pints of the usual straw-coloured ovarian fluid. After all the fluid had come away there remained a solid, immovable tumour, which occupied the whole of the abdomen below the level of the umbilicus. The operation relieved the dyspnoea greatly, and she was able to lie down and have some refreshing sleep. Her pulse, too, became firmer and larger, though its frequency was as great as before. After a few days it became apparent that the tumour was refilling rapidly, and by the end of May it was as large as ever, and her distress became so great that I could not resist her importunities to be relieved at any risk. Having got a large trocar and canula made in the bazaar, I proceeded to remove the tumour on the 4th of June, 1867. assisted by Assistant-Surgeon C. A. Maunsell, R.H.A.' Staff Assistant-Surgeon J.Jones; and Sub-Assistant-Surgeon Ram Lall Ghose. The weather at the time was intensely dry and hot. The operation took place at six in the morning. The thermometer in the shade then marked $90^{\circ} \mathrm{F}$., the wet bulb standing at $69^{\circ} \mathrm{F}$. At 4 P.M. the dry bulb stood at $112^{\circ} \mathrm{F} . ;$ the wet bulb $71^{\circ} \mathrm{F}$.

The tumour being exposed, I found it in every direction so firmly adherent to the abdominal parietes that for a moment I despaired of being able to remove it; but, remembering that a miserable death to the woman would be the certain result of its being suffered to remain, I took courage, and, by tearing and cutting, with great labour I at last succeeded in freeing the tumour from its anterior attachments; but it was so firmly attached posteriorly that very forcible traction had to be applied for some minutes before it gave way. The pedicle, which was short and thick, was first tied in two parcels with a horsehair ligature, made of five horsehairs twisted and doubled so as to form a pretty strong rope. The second parcel being tied, the ligature was turned back so as to include the whole pedicle in one noose. One end of the ligature was cut off, and the other brought out, the end of the pedicle being fixed in the external wound in the usual way with a needle. The abdominal wound was closed in the usual way with deep-set needles and superficial horsebair sutures. As soon as she had recovered from the effects of the chloroform the patient took a dose of one drachm of laudanum, and soon fell asleep. She had not a bad symptom afterwards. She was fed on bread-and-milk, and good soup made of beef extract. Her bowels remained unmoved for five days, and she was unable to pass urine without the aid of the catbeter till the oth, when she regained full control over the bladder. Her bed was lifted out of the ward every evening, and placed in the open air, where she slept through the night.

As soon as the patient got strong, sho became very impatient to have the pedicle ligature removed; but up to the 24.th June it showed no signs of coming away. On the $26 \mathrm{th}$, in my absence, she tugged at it herself in hopes of getting it out; and her violence brought on severe pain and tenderness all over the abdomen, which looked very sericus for a time, but hot ponltices and a large opiate dissipated the danger. Up to the 28th July the ligature remained firmly attached, and, as she was getting greatly annoyed at what she regarded as an unseemly blemish, I cut it of as deep in the wound as I could reach with the point of a scissors. She was discharged from hospital the same day.

On the 11th October she rode-in twenty miles on a pony to ask my advice for a neighbour who had a large spleen. She looked remarkably well, sleek, fat, and well-thriven, 
At the point of exit of the ligature there was a small papilla, from which a drop of watery fluid exuded.

The tumour was multilocular. The solid portion weighed $14 \mathrm{lb}$., the fluid portion about $28 \mathrm{lb}$.

I was led to use horsehair as a ligature in this case by my experience of its advantages as a suture in several rhinoplastic operations. It appeared to me to have all the advantages of silver wire as a suture. It did not act like a seton, and lead to the formation of pus, as the ordinary thread suture did. It appeared to canse no more irritation in the tissues than does a gold or silver ving in a roman's nose or ears. At the time of the operation I was under the impression that a horsehair ligature wonld have cut itself out as the thread suture does, but in the present case it is certain that it has not done so; and from a few experiments made subsequently on dogs, I have reason to believe that a horsehair ligature would very rarely if ever become detached. I castrated a dog, tying the spermatic cord with one horsehair. After two months the dog was killed, when I found the end of the cord firmly agglutinated to the adjacent tissues, and encircled by the hair just as when it was first applied; the end of the cord distal to the ligature had been reduced to a semi-ligamentous condition, owing to the diminished circulation of blood in it. I also tied the femoral artery of a dog with a horsehair, and the external wound was closed up with horsehair sutures. Though the animal licked the sutures out, the wound after a time healed up; and when, three months afterwards, the animal was killed, the ligature was found in situ on the occluded artery. The same experiment performed on the carotid artery gave a similar result; but in this case, the animal being unable to lick the sround, it healed up by the first intention, and so well that I had great difficulty in discovering the cicatrix at the post-mortem. In an amputation of the forearm of a woman I tied the radial, ulnar, and interosseous arteries with one horsehair each, both ends of the ligature being cut off close to the vessels, and closed the wound with horsehair sutures. The wound healed very rapidly and almost by the first intention, and the patient appeared to suffer less pain than I had before observed in any similar amputation. The ligatures were carefully looked for, but never made their appearance, and I believe they remained in situ on the vessels.

The case of Miriam renders it, I think, probable that horsehair would prove a very valuable material for ligatures in ovariotomy. One horsehair would be found quite strong enough to arrest hæmorrhage from the pedicle, or from any vessels that might require to be tied in the course of the operation. The pressure exerted by a horsehair might be made at least equal to that which suffices to arrest hæmorrhage by acupressure. A pedicle ligatured with a horsehair might, I believe, be dropped into the pelvis with an almost entire freedom from risk of suppurative inflammation.

Kingstown, February, 1871.

\section{REMARKS}

ON THE GUNSHOT WOUNDS OF THE WAR, THEIR NATURE, AND THE TREATMENT ADOPTED IN THE FIELD HOSPITALS.

\section{BY SANDFORD MOORE, B.A.,} ASSISTANT-SURGEON ATH DRAGOON GUARDS.

As I had the honour of being selected by the DirectorGeneral of the Army Medical Department to accompany the ambulance equipped and despatched to France in October last by the Society for Aid to the Sick and Wounded in War, and as I remained with it in the Prussian lines from that time until the end of the war, the following remarks, which I select from my notes, may be found worthy of a place in THe LANCET.

I had opportunities of seeing wounded, not alone in what one might call the permanent hospitals, as at Versailles, Orleans, Chartres, and other towns, but also (since the ambulance accompanied the ambulance column of the Prussians) immediately after the wounds were inflicted on the field. Amongst this number I have seen but one sabre wound; the remainder have been caused either by bullets or shells, or hy objects set in motion by these, such as splinters of wood. I have not seen a bayonet wound.

The shell wounds have varied in every degree of severity, from proving instantly fatal to one or more men to the mere flesh scrotch. 'The bullot wotnds, no less fatal, demanded the surgeon's attention not alone from the injury inflicted on the parts, but from the eccentric course sometimes taken by the ball. One bullet dropped down a man's trowsers and foll into his boot, having previously passed through both thighs, scrotum, and prepuce, making in all eight wounds caused by this one ball. Another I have seen where the ball lodged in and was subsequently extracted from the right iliac region, having before this passed through the left elbow-joint and across the abdomen. And a third exemplifying the erratic passage of the ball: A soldier received a bullet wound of the left thigh; and this was the only one which could be discovered about this extremity, or, in short, his only wound; nevertheless, a bullet was found lodged in his right thigh, a short way above his knee, and was subsequently extracted. Where was the wound of entrance? I presume it was on the opposite thigh, and the ball must then have travelled round by the pelvis to where it was found lodged.

I have seen but one wound said to be the result of an explosive bullet, and this was most probably a shell wound. The man was a Prussian soldier. The lower maxilla, integument, tongue (all but the root), and muscles had been torn away.

On the whole, wounds of the lower extremity have been more frequent than those of the upper; this has resulted, no doubt, from the long ranges at which the firing took place. Both chassepôt and Prussian and Bavarian bullets split the shafts of the long bones alike. At the commencement of the war it was considered that the chassepot bullet did not; I have had frequent opportunities of seeing that it does.

The differences observed in the size and appearance of the wounds of exit and entrance have not, in a great number of cases, been quite so apparent as those laid down in the books. It greatly depended upon the velocity with which the bullet was travelling. The greater the velocity, the less the difference between the two, and vice verso 0 ; and this held good even when substances offering considerable resistance, such as the shafts of the femora, had to be traversed.

That the powers of the German of enduring pain with both patience and fortitude are greater than those of the French soldier I think is undisputed on all sides; and this higher vitality makes no small element in the cure of wounds. I fancy that I have seen more cases of traumatic delirium and irritative fever amongst the French, and more inclination for wounds to become foul and take on unhealthy action, coeteris paribus, than among the German wounded.

Under the head of treatment I would make some remarks on :-1. Amputations (the time chosen by Prussian surgeons) and excisions. 2. The uses of carbolic acid during the war. 3. Remarks on some special splints, the Trathosen, \&c. 4. Some Prussian hospital appliances, the Esmarch bind, \&c.

1. There are two operations which the whole experience of the war goes to show should be abandoned, at any rate in field hospitals, or until all further necessity for moving the patient is ended-viz. (a) excision of the knee-joint; (b) amputation by the flap method in the upper or middle third of the leg.

(a) As to excision of the knee-joint. These cases have proved exceedingly fatal. Prof. Nusbaum, of Nunich, has performed this operation more frequently than any other surgeon dnring the war-between thirty and forty times. I have been given to understand, from a good source, that the operation has not met with success, even at his hands-not with such success as to justify its continuance in war time. And in my endeavours to sift the matter amongst both French ambulance surgeons and many Prussians, I have always received the same answer, that their cases died. The only case I assisted at I was unable to watch in its progress, owing to my being obliged to push on with the army; but I have since been informed that this one also ended fatally. During the latter part of the campaign, in the operations about Vendome and Le Molns, this operation has been abandoned by military surgeons, and amputation throngh the joint, or above it, performed instead. I understand that 